\title{
ASSISTIVE TECHNOLOGIES FOR BRAIN-INJURED GAMERS
}

\author{
Jason Colman ${ }^{1}$ and Paul Gnanayutham ${ }^{2}$ \\ ${ }^{1}$ SAE Institute, United House, North Road, London, N7 9DP, United Kingdom, \\ +44 (0) 207923 9159, j.colman@sae.edu \\ 2 Department of Computing, University of Portsmouth, Buckingham Building, \\ Lion Terrace, Portsmouth, PO1 3HE, United Kingdom, \\ +44(0) 239284 6404, paul.gnanayutham@port.ac.uk
}

\begin{abstract}
This paper surveys assistive technologies which make video games more accessible for people who have an acquired brain injury (ABI). As medical care improves, an increasing number of people survive ABI. Video games have been shown to provide therapeutic benefits in many medical contexts, and rehabilitation for ABI survivors has been shown to be facilitated by playing some types of video game. Therefore, technologies which improve the accessibility of games have the potential to bring a form of therapy to a larger group of people who may benefit. Hardware technologies which may make games more accessible for brain injury survivors are considered. These include brain-computer interfaces, head and eye tracking, and mouth controllers.

Complementing these devices, game developers should incorporate accessibility features into their games during the development process. The dissemination of best practice guidelines among game development practitioners would improve accessibility and thus the therapeutic potential of future games.
\end{abstract}

\section{INTRODUCTION}

Any brain injury which occurs after birth is called an acquired brain injury (ABI). Causes of ABI include stroke, tumours, degenerative diseases, demyelinating conditions and infectious disorders (Murdoch \& Theodoros, 2001). A traumatic brain injury (TBI) is an ABI caused by trauma such as a blow to the head, an impact with a blunt object, or penetration by a sharp object. Common causes of TBI are motor vehicle accidents; bicycle accidents; assaults; falls and sports injuries (Hyder et al., 2007). Motor vehicle accidents are the most common cause of TBI globally (Hyder et al., 2007), although for children this may be as a pedestrian or cyclist rather than passenger (Murdoch \& Theodoros, 2001).

Theodoros et al. state "The prevalence of TBI in modern society has reached epidemic proportions" (2001, p. 27): Hyder et al. (2007) estimate that 10 million people per year are affected by TBI globally. TBI is especially prevalent in Low and Middle Income Countries, where the risk factors tend to be higher, and health systems are inadequately prepared. Road traffic injuries in Latin America and Sub Saharan Africa are the main cause of a higher TBI incidence in these regions.

For people who have suffered a brain injury, rehabilitation is the process of regaining lost skills, or developing coping mechanisms to replace them. The goal is for a cognitively impaired person to function safely, productively and independently (Mateer, 2005). Cicerone et al. (2000) stress that the aim of cognitive rehabilitation services is to improve a person's function in areas relevant to their everyday lives. Mateer (2005) highlights some general principles for successful cognitive rehabilitation. These are: the need to take an individualised approach; to involve clients and caregivers in all aspects; and clear and realistic goal setting. Mateer (2005) notes that most successful interventions involve multiple, eclectic approaches. One such approach could be the use of video games as therapy: this paper looks at ways in which video games can be made more accessible for people who have survived brain injury, and how awareness can be raised among game developers. 


\section{VIDEO GAME THERAPY FOR BRAIN INJURIES}

Video games tend to receive quite a lot of negative press, but have been used in a wide variety of therapeutic contexts for over 25 years (Griffiths et al., 2005), including helping people who have a brain injury. To give some examples: Sietsema et al. (1993) report the use of an electronic table-top game to promote arm reach for people who have suffered a TBI. Betker et al. (2007) have used bespoke serious games to promote balance for people with spinal cord and traumatic brain injuries. Burke (2009) and colleagues have developed a suite of serious games designed to aid recuperation after a stroke. This is accomplished by requiring the player to make repetitive arm movements which aid upper limb recovery. O'Connor (2000) and team developed a wheelchair interface to computer games called Game Wheels. This interface motivated spinal cord injury patients to exercise more regularly, by controlling games by driving their wheelchair. Galego and Simone (2007) developed a simple memory matching game which is played within the Second Life virtual environment, enabling the user and therapist to meet virtually. The game is controlled by the Nintendo Wii remote ("Wiimote"), and so exercises motor as well as cognitive skills. The authors state that playing this type of game can be a powerful rehabilitation activity, in areas such as upper extremity rehabilitation after a stroke. Katz et al. (2005) conducted a study into the effectiveness of a virtual reality (VR) program to train stroke patients to cross roads safely. The participants suffered from unilateral spatial neglect as a result of the stroke. In this condition, patients will ignore objects or people on one side. The VR treatment was found to be effective in improving visual-spatial skills, and particularly, improved the ability to cross roads safely.

So, video games definitely have a place in physical therapy for ABI survivors; unfortunately commercial games are not always accessible.

\section{ACCESSIBILITY HARDWARE FOR GAMERS}

Many disabled people are prevented from playing video games. Practically all games require the user to be able to hold a controller, and manipulate the controls quickly and accurately in order to progress in the game. People with disabilities may be prevented from doing this due to the design of the controllers, the reaction speed required, the dexterity and accuracy required, and so on.

Controller technology is evolving, but not necessarily in a more accessible direction. The three major console manufacturers have introduced controller hardware which is radically different to the classic joystick. These advances in controller technology assume able-bodied players, who can precisely aim a remote (in the case of the Wii) or precisely move their whole bodies (in the case of Microsoft ${ }^{\circledR}$ Kinect for the Xbox 360®). Work has been done in making games accessible to disabled people. Ellis (2009) describes how PCs and game consoles can be made accessible, for instance by replacing standard controllers with large individual switches. These can be placed around the player allowing a game to be played using any combination of body movements.

For gamers who are severely motor impaired, a brain-computer interface $(\mathrm{BCI})$ could be an appropriate enabling interface. In this section we review BCIs and their applicability to video game control.

Bio-potentials are electrical signals originating in the brain and nervous system. A BCI may use any of the bio-potentials which are under the conscious control of the user (Wolpaw et al., 2002). Typically BCIs measure the electroencephalographic (EEG) waveform generated by the brain, eye motion (electromyography) and muscle activity (electrooculography). Several low-cost BCI headsets are available, aimed at the games market. Table 1 shows some currently available assistive technology which can be used to play games, including the low-cost BCI devices. 
Table 1. Commercially available accessibility hardware

\begin{tabular}{|l|l|l|}
\hline Name & Manufacturer & Type \\
\hline Neural Impulse Actuator ${ }^{\mathrm{TM}}$ & OCZ Technology & BCI \\
\hline EPOC (fig. 2) & Emotiv & BCI \\
\hline MindSet (fig. 1) & NeuroSky & BCI \\
\hline SmartNav ${ }^{\text {TM }}$ (fig. 4) & Natural Point ${ }^{\circledR}$ & Head motion tracker \\
\hline ViVo Mouse $^{\mathrm{TM}}$ & Vortant Technologies, LLC & $\begin{array}{l}\text { Head-tracking and voice- } \\
\text { tracking sofware }\end{array}$ \\
\hline EeZee Mouse & LaZee Tek & Body motion tracker \\
\hline Tracker Pro® ${ }^{\circledR}$ & Madentec Inc. & Head motion tracker \\
\hline Headmouse ${ }^{\circledR}$ & Origin Instruments Corp. & Head motion tracker \\
\hline EyeGuide & Grinbath & Eye gaze tracking \\
\hline Integra Mouse (fig. 3) & LIFETool & Mouth controller \\
\hline QuadJoy (fig. 5) & SEMCO & Mouth controller \\
\hline IntelliSwitch & Madentec Inc. & $\begin{array}{l}\text { Sip/puff controller for } \\
\text { left/right mouse button } \\
\text { clicks }\end{array}$ \\
\hline
\end{tabular}

Regarding the consumer BCI devices, the number of sensors is far fewer than for medical or research grade EEG machines, and so this hardware may not be up to the task of controlling real time video games: Halley (2010) expresses scepticism that the Emotiv or Neurosky devices will actually be used for gaming "any time soon". Graimann et al. (2011) state that most computer games cannot be played using a BCI because of the bandwidth limitations. Bos et al. (2010) note that for controlling games, BCIs are slower and less accurate than other modalities, and require extensive training. Other researchers do report success in controlling games using BCI, at least in the lab. Jackson et al. (2009) used a BCI to control a first-person shooter-style game.

The promise of BCI gaming is not yet a reality, then. More success has been achieved using eye gaze tracking to effectively control real time games such as racing games. Eye tracking systems determine the point on the screen at which the user is focused. Most eye tracking systems work using infra red light, so as not to dazzle the user. The IR light reflected by the eye forms a bright circle at the pupil. A smaller point of IR light is reflected due to the corneal reflection, (also called the first Purkinje image). The vector from the pupil centre to the corneal reflection is processed to give the gaze direction (Poole \& Ball, 2005). Another form of AT is a mouth-controlled joystick (e.g. Jouse, QuadJoy, Integra Mouse). These interfaces incorporate sip (suck) and puff (blow) sensors to enable left and right mouse click actions.

\section{VIDEO GAME ACCESSIBILITY GUIDELINES}

To improve accessibility for any software, including games, Universal Design principles apply, defined by Dix et al. as "...the process of designing products so that they can be used by as many people as possible in as many situations as possible" (2004, p. 366). This can be achieved by designing in redundancy, or by supporting assistive technologies. Universal Design is based on seven principles proposed by Story et al. (1998). These seven principles are: equitability - no user should be excluded or stigmatised; flexibility; simplicity; clarity; error tolerance; low physical effort requirements; and sufficient size and space for use. Multi-modal interaction is recommended, providing access to information through more than one mode of interaction. This both enhances the richness of interaction, and also guards against excluding a group of users.

For video games, the user experience is honed over the course of the production process using game usability methodologies, which can be quite different to the usability methodologies followed for 
productivity software. As a particular example, Nielsen's (1993) Discount Usability methods are not appropriate for group or 'party' multi-player games, as the user experience is based on social interaction (Amaya et al., 2008).

The issue of video game accessibility has led to the formation of organisations which identify and disseminate good practice. The International Game Developers Association Game Accessibility Special Interest Group (IGDA-GASIG, www.igda-gasig.org) publishes a list of the most important ways in which game developers can make their games playable by a wider audience.

The "top ten" guidelines for video game accessibility are:

1. Allow controller reconfiguration;

2. Provide alternative controller support;

3. Offer sound alternatives;

4. Provide separate volume controls for music, sound effects and dialogue;

5. Provide high visibility graphics;

6. Be colour-blind friendly;

7. Provide difficulty level and speed adjustment;

8. Offer practice modes;

9. Make menus as accessible as possible; and finally,

10. Publicise the accessibility features and game requirements.

The 2012 Global Game Jam (www.globalgamejam.org) featured an Accessibility Challenge, where the participants were invited to develop games which incorporated as many of these guidelines as possible. Events such as this disseminate these guidelines in an important way: many of these participants will be part of the 'next generation' of game developers.

\section{SUMMARY AND CONCLUSIONS}

Some disabled video game players are prevented from playing their choice of game due to accessibility limitations caused by the game controller or the game itself. Although assistive technologies are often thought of as specialised hardware peripherals, video game AT also encompasses game software development best practice for accessibility. Video games can be made more accessible by individual end users, by modifying hardware or using off-the-shelf AT hardware instead of standard controllers. Several low-cost BCI peripherals have recently appeared on the market, aimed specifically at the gaming market; the challenge is to make these devices really usable. Other forms of AT include switches, head-mounted pointers, sip and puff controllers, and eye gaze technology.

Another approach is to make the games more accessible, by following guidelines set by IDGAGASIG and other groups, and by incorporating principles of Universal Design into the games. The advantages of making video games more accessible go far beyond the economic advantage of increasing the target market for a game, and the ethics of excluding between 10 and 20 percent of the population. Video games have been shown to provide therapeutic medical benefits in so many contexts, that making games more accessible opens up their beneficial potential to many more people.

The authors believe that further research is called for in a number of areas. For one, can the 'gaming' BCIs recently introduced really be used for this purpose? BCIs are typically hard to use without training, and so, although BCI-controlled games have had some success in laboratory settings, advances in this direction would be welcome. Further research would further refine and evaluate the guidelines for game accessibility proposed by organisations such as IGDA-GASIG. As best practice guidelines for game accessibility are formed, they must be disseminated to the practitioners who 
can incorporate them into the video games of the future.

\section{References}

Amaya, G., Davis, J., Gunn, D., Harrison, C., Pagulayan, R., Phillips, B., and Wixon, D. (2008) Games User Research (GUR): Our experience with and evolution of four methods. In: Ibister, K., and Schaffer, N. (Eds.) Game usability: Advice from the experts for advancing the player experience. Burlington, MA: Morgan Kaufmann Publishers

Betker, A., Desai, A., Nett, C., Kapadia, N., and Szturm, T. (2007) Game-based exercises for dynamic short-sitting balance rehabilitation of people with chronic spinal cord and traumatic brain injuries. Physical Therapy 87 (10): 1389-1398

Bos, D. P.-O., Reuderink, B., van de Laar, B., Gürkök, H., Mühl, C., Poel, M., Nijholt, A., and Heylen, D. (2010) Brain-computer interfacing and games. In Tan, D., and Nijholt, A. (Eds.), BrainComputer Interfaces. London: Springer-Verlag

Burke, J.W., McNeill, M., Charles, D., Morrow, P., Crosbie, J., and McDonough, S. (2009) Optimising engagement for stroke rehabilitation using serious games. Visual Computing 25: 10851099

Cicerone, K. D., Dahlberg, C., Kalmar, K., Langenbahn, D. M., Malec, J. F., Bergquist, T. F., Felicetti, T., Giacino, J. T., Harley, J. P., Harrington, D. E., Herzog, J., Kneipp, S., Laatsch, L., and Morse, P. A. (2000) Evidence-based cognitive rehabilitation: Recommendations for clinical practice. Arch Phys Med Rehabil 81 (December)

Dix, A., Finlay, J., Abowd, G., \& Beale, R. (2004) Human-computer interaction ( $3^{\text {rd }}$ edn). Harlow: Pearson Education

Ellis, B. (2009) OneSwitch.org.uk website. http://www.oneswitch.org.uk/ Retrieved 15 April 2012

Galego, B., and Simone, L. (2007) Leveraging online virtual worlds for upper extremity rehabilitation. Bioengineering Conference, 2007. NEBC '07. IEEE 33rd Annual Northeast: 267-268, 10-11 March 2007

Graimann, B., Allison, B.Z., and Pfurtscheller, G. (2011) An introduction to brain - computer interface (BCI) systems, In: Graimann, B., Allison, B.Z., \& Pfurtscheller, G. (Eds.) Brain-Computer Interfaces: Revolutionizing Human-Computer Interaction. Springer Publishing

Griffiths, M.D. (2005) Video games and health. British Medical Journal 331: 122-123

Halley, D. (2010) App lets you make a phone call with your mind. http://singularityhub.com/2010/08/12/app-lets-you-make-a-phone-call-with-your-mind-video/ Retrieved 15 April 2012

Hyder, A., Wunderlich, C., Puvanachandra, P., Gururaj, G., and Kobusingye, O. (2007) The impact of traumatic brain injuries: A global perspective. NeuroRehabilitation 22

Jackson, M.M., Mappus, R., Barba, E., Hussein, S., Venkatesh, G., Shastry, C., and Israeli, A. (2009) Continuous control paradigms for direct brain interfaces. In Jacko, J. (Ed.): HumanComputer Interaction, Part II, HCII 2009, LNCS 5611: 588-595. 
Katz, N., Ring, H., Naveh, Y., Kizony, R., Feintuch, U., and Weiss, P. (2005) Interactive virtual environment training for safe street crossing of right hemisphere stroke patients with Unilateral Spatial Neglect. Disability and Rehabilitation 29 (2): 177 - 181

Mateer, C. (2005) Fundamentals of cognitive rehabilitation. In Halligan, P., and Wade, D. (Eds.) Effectiveness of rehabilitation for cognitive defects. Oxford University Press

Murdoch, B., and Theodoros., D. (2001) Epidemiology, neuropathophysiology, and medical aspects of traumatic brain injury. In Murdoch, B., and Theodoros., D. (Eds.) Traumatic Brain Injury: Associated speech, language and swallowing disorders. San Diego, CA: Singular Publishing Group

Nielsen, J. (1993) Usability Engineering. San Francisco, CA: Morgan Kaufmann

O'Connor, T. J., Cooper, R. A., Fitzgerald, S. G., Dvorznak, M. J., Boninger, M. L., VanSickle, D. P., and Glass, L. (2000) Evaluation of a manual wheelchair interface to computer games.

Neurorehabil Neural Repair 14

Poole, A., and Ball, L. J. (2005) Eye tracking in human-computer interaction and usability research. In Ghaoui, C. (Ed.) Encyclopedia of human computer interaction. Idea Group, Pennsylvania: 211219

Sietsema, J., Nelson, D., Mulder, R., Mervau-Scheidel, D., and White, B. (1993) The use of a game to promote arm reach in persons with traumatic brain injury. American Journal of Occupational Therapy 47 (1)

Story, M., Mueller, J., and Mace, R. (1998) The Universal Design file: Designing for people of all ages and abilities (Revised edition). State University, NC: Center for Universal Design

Theodoros, D. G., Murdoch, B. E., and Goozée, J. V. (2001) Dysarthria following traumatic brain injury: Incidence, recovery, and perceptual features. In Murdoch, B., and Theodoros., D. (Eds.) Traumatic Brain Injury: Associated speech, language and swallowing disorders. San Diego, CA: Singular Publishing Group

Wolpaw, J. R., Birbaumer, N., McFarland, D. J., Pfurtscheller, G., and Vaughan, T. M. (2002) Brain-computer interfaces for communication and control. Clinical Neurophysiology 113: 767-791

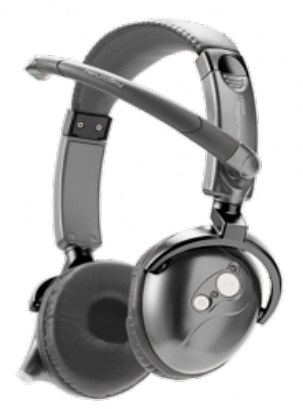

Figure 1. NeuroSky MindSet. Reproduced with permission. 


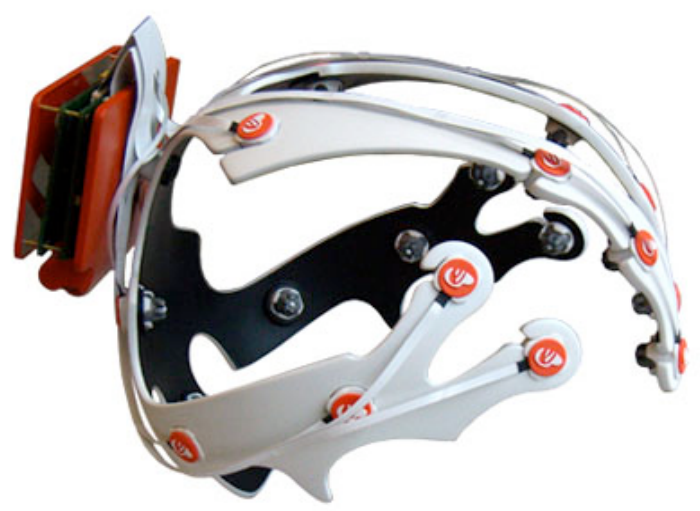

Figure 2. Emotiv EPOC. Reproduced with permission.

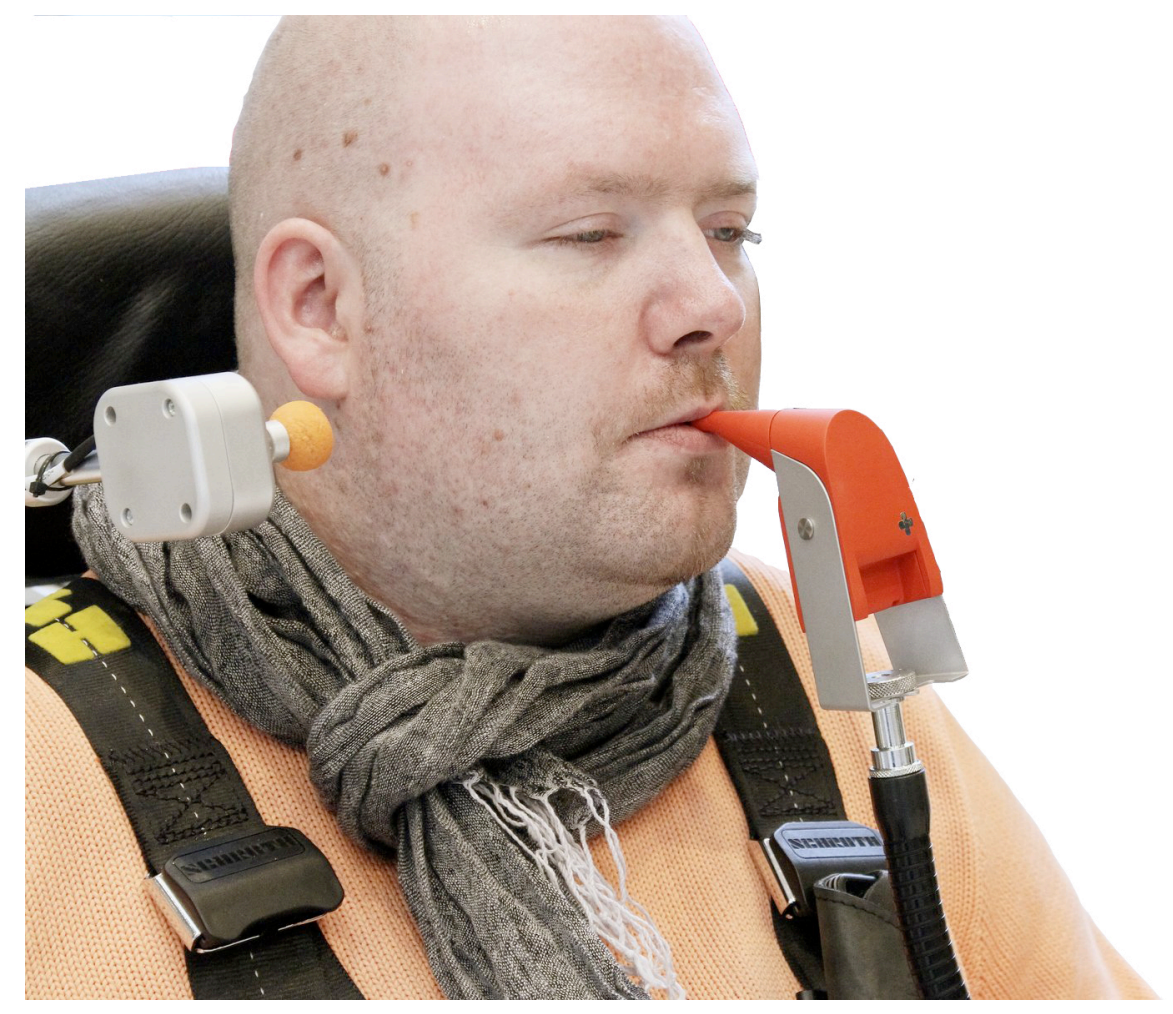

Figure 3. LIFETool Integra Mouse. Image (C) Copyright LIFETool. 


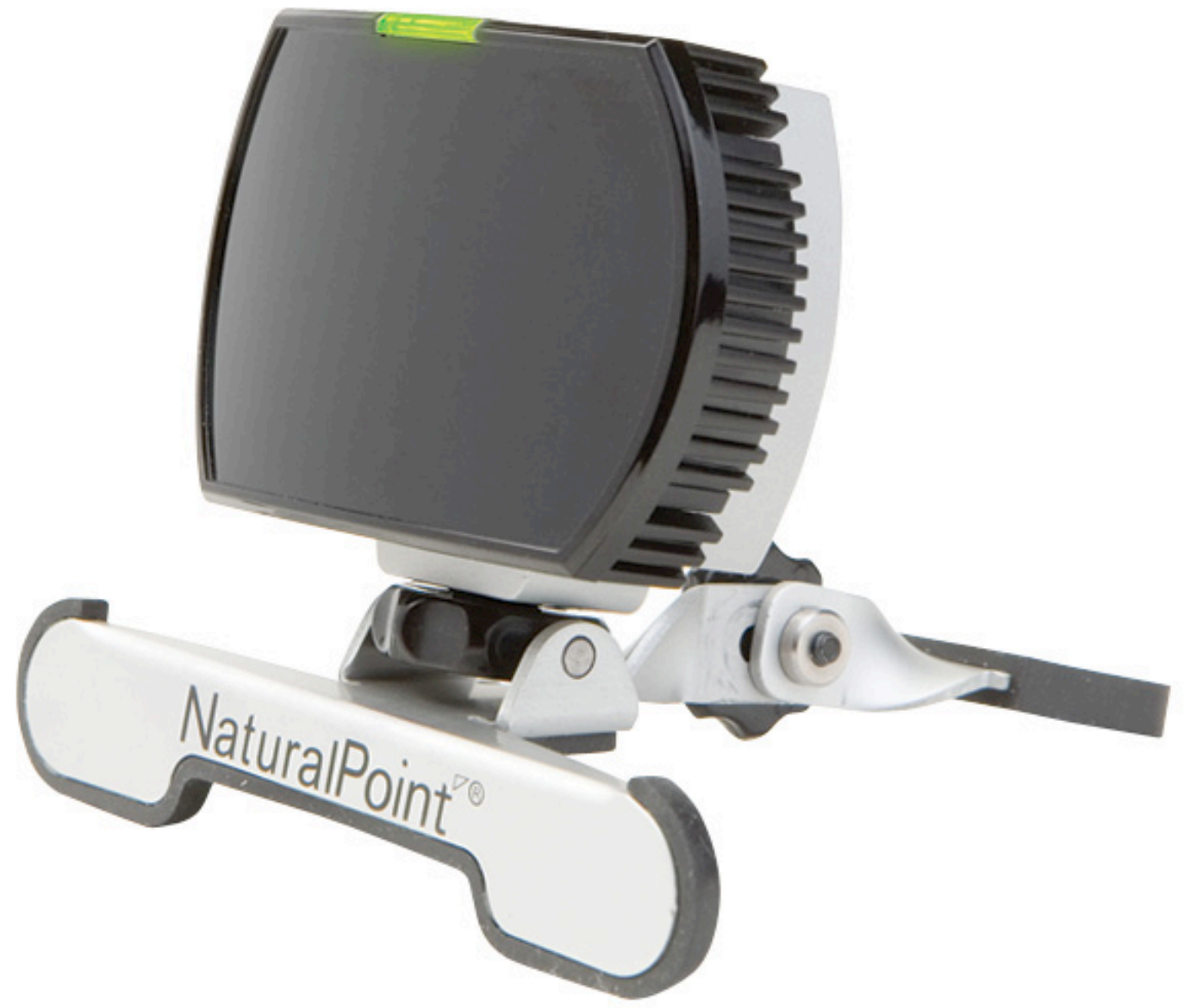

Figure 4. SmartNav 4. Image (C) Copyright NaturalPoint, Inc.

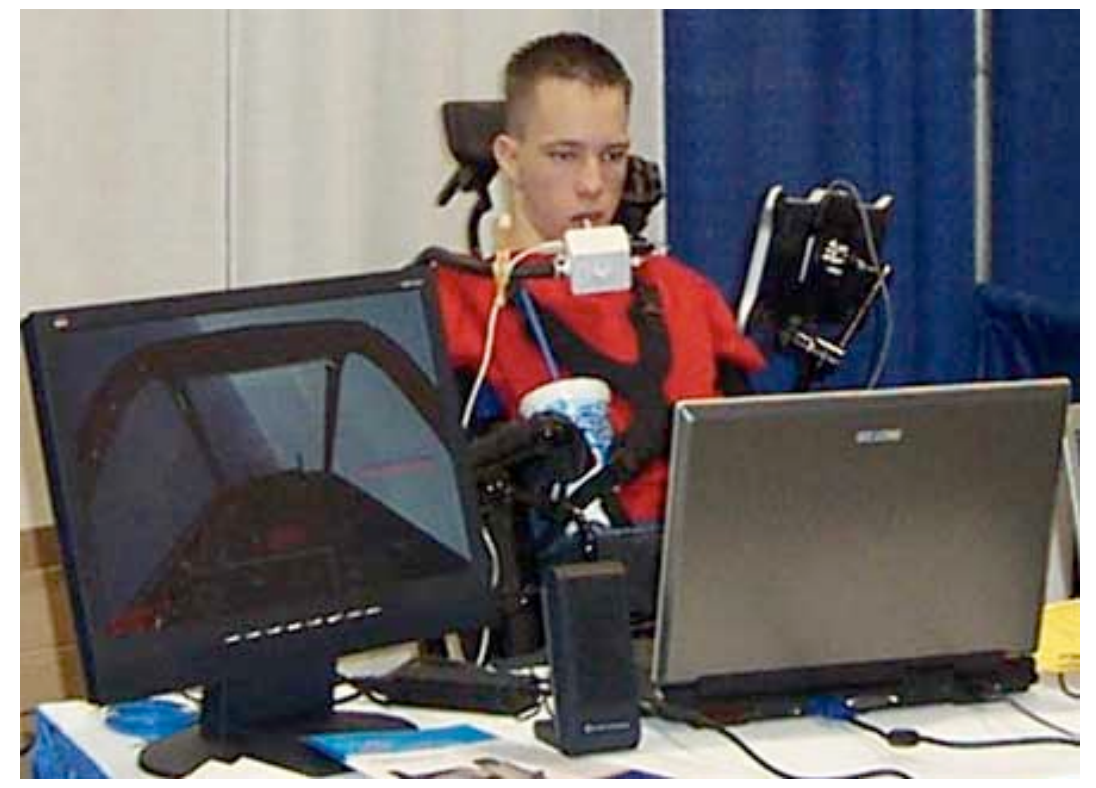

Figure 5. QuadJoy. Copyright (C) 2012 United Spinal's Action Online Magazine 